\title{
Assistência Educacional De Mecânica Para Motoristas
}

\section{Mechanical education assistance for drivers}

LOPES, Eduardo Oliveira; Estudante; FUCAPI

edu.sicsu@gmail.com

TRINDADE, Agatha Araújo; Mestre; FUCAPI

agatha.a.trindade@gmail.com

COSTA, José Vitor da Silva; Estudante; FUCAPI

josevitor.dsc@gmail.com

\section{Resumo}

Este trabalho apresenta o resultado de um projeto que analisou os conhecimentos atuais dos motoristas e estudantes de Autoescola quanto a funcionamento de seus carros e de como resolvêlos, ou ao menos diagnosticá-los. Este projeto possui caráter descritivo-analítico, com abordagem quantitativa. $\mathrm{O}$ estudo registrou e catalogou a carência de conhecimento dos usuários. Para tal, fora desenvolvida uma solução prática para este problema usando os fundamentos do Design de Interface e Interação. O objetivo e contribuição principal deste trabalho é fornecer um meio de facilitar o aprendizado destes motoristas e estudantes de conhecerem a mecânica de seus veículos, desconstruindo a complexibilidade das informações oferecidas a eles em uma plataforma mobile.

Palavras Chave: Design Instrucional; Métodos de Ensino; UI/UX Design.

\begin{abstract}
This paper presents the results of a research that analyzed the current knowledge of drivers and driving students in Manaus, Brazil, about their cars' operation problems and how to solve them, or at least diagnose them. This research has a descriptive-analytical feature with a quantitative approach, and the study registered and cataloged the user's lack of knowledge. For that, a practical solution was developed to this problem based on the fundamentals of Interface Design and Interaction Design. The main objective and contribution of this paper is to provide a way of facilitating the learning process of these drivers and students to know the mechanics of their vehicles, deconstructing the complexity of the information offered to them through a mobile platform. Keywords: Instruction Design; Teaching Methods; UI/UX Design.
\end{abstract}




\section{Introdução}

"Temos de ter consciência de que não basta abastecer o veículo", a afirmação é de Marco Fuzatto (2011), orientador de prática profissional do Senai-SP. Conhecer o funcionamento do carro é algo primordial para todo motorista, no entanto, as coisas não funcionam exatamente dessa forma, já que muitos motoristas não possuem o conhecimento sequer para manter o carro funcionando dentro do que é considerado necessário para sua segurança e de outros a sua volta. O problema não se encontra somente na capacidade de aprendizado do motorista já que muitas da autoescolas não possuem equipamento ou a capacidade de transmitir essas informações de forma eficiente. Nesse sentido, o material disponibilizado para os motoristas é muitas vezes ineficaz ou complexo demais para pessoas mais leigas, desta forma, afastando-os de qualquer interesse relacionado a estes ensinamentos.

Contudo o presente artigo tem o objetivo de criar de um meio que possa transmitir tais informações de modo mais simples e adaptado aos motoristas e estudantes de autoescola, que não disponibilizam de tempo ou mesmo interesse para se aprofundar na mecânica de seu veículo. 0 objetivo principal deste trabalho é propor uma forma de estruturar essa informação por um contexto ágil para estes motoristas, e assim, fazê-los aprender.

\section{Delimitação do Problema}

Problemas com o automóvel é algo que praticamente todos os motoristas possuem. Em 2012, foi feito um levantamento da polícia rodoviária federal das principais causas de acidentes declaradas pelos próprios motoristas e a falha mecânica ocupa a quarta posição das principais causas de acidentes declaradas pelos motoristas. Em 2006, a Polícia Rodoviária Federal atuou 17.914 veículos por circularem sem as mínimas condições em rodovias brasileiras, conforme dados do Denatran Departamento Nacional de Trânsito.

E em outro estudo realizado desta vez pela ONSV (OBSERVATÓRIO Nacional de Segurança Viária), fora levantado dados a respeito dos acidentes de trânsito, e segundo a entidade $90 \%$ dos acidentes ocorreram por falhas humanas, que variam desde a negligência da legislação até a falta de manutenção do veículo. Que pode ser abordada melhor pela pesquisa do Instituto Scaringella de Trânsito feita em 2016, em que a falta da manutenção preventiva do veículo está relacionada a 30\% dos acidentes no trânsito, e que cerca de $80 \%$ dos entrevistados tinha problemas como pneus carecas, lanternas queimadas, falta de seta e motores desregulados.

Estes problemas acima estão relacionados diretamente a forma de como o motorista usa seu carro, contudo, nem todos os problemas derivam do uso inadequado dos veículos, pois, não é raro que os carros demandem de recalls das montadoras devida à falhas na produção, como exemplo dos modelos do Gol, Golf, Voyage e Up! da Volkswagen de 2018, e do Palio e Strada da Fiat nas produções de 2016 e 2017. Todas essas situações causam estresse ao motorista e são ainda mais desconfortáveis quando o ele acaba de tirar a sua carteira. Esta situação é incômoda e pode piorar pelo fato de que a maioria dos motoristas saem da escola de direção sem o mínimo conhecimento de como lidar com estes problemas, e as fontes onde eles podem se informar geralmente dispõem de uma linguagem muito complexa, os levando a casos de estresse, ou postergar o problema.

Isso pode ser muito sério, pois, o fato de não conhecer o seu veículo o põe em situações de risco tais como serem enganados por mecânicos mal-intencionados ou inexperientes que podem causar prejuízos financeiros, ou em casos mais extremos falhas no funcionamento do veículo podendo ocasionar até mesmo acidentes graves. 


\section{Justificativa}

O fato se deve a maior parte do motoristas se formar sem o conhecimento básico de como funcionar o motor de um carro. Segundo Fuzatto (2011), "Os conhecimentos básicos que o proprietário do automóvel deve ter estão diretamente relacionados aos princípios de funcionamento dos componentes".

Isso é necessário para qualquer motorista, entretanto, esse conhecimento não é passado nas escolas de direção. Cursos externos até passam este conhecimento, contudo os motoristas não conseguem aprender ou simplesmente lhes há falta de interesse nessas aulas. É imprescindível que os mesmos tenham ao menos o conhecimento básico para sua própria segurança no trânsito, elucidar as dúvidas dos motoristas quanto à mecânica do seu carro por meios convencionais, tais como exemplo os manuais distribuídos pelas próprias montadoras não tem sido eficiente já que a linguagem mais técnica e um empecilho para aqueles que são mais leigos.

O recurso que pode ser utilizado nessa questão pode ser uma plataforma Mobile que tenha uma linguagem mais simples e acessível para os motoristas evitando sobrecarregá-los com a quantidade de informação massiva, pois desta forma evita-se que os mesmos percam o foco revelando a informação gradativamente de maneira mais harmoniosa e para isso é necessário um bom uso do UI/UX, visto que, uma distribuição mais equilibrada da informação fará com que o motorista dificilmente se perca ao usá-lo.

\section{Referencial Teórico}

\subsection{Educação no Trânsito}

As referências relacionadas à Marco Fuzatto (2011), na introdução e justificativa deste artigo, se devem a necessidade de informações congruentes a carência dos motoristas quanto ao conhecimento geral da mecânica. Pelo ponto de vista de um profissional da área da educação, já que o mesmo é orientador de prática profissional do Senai-SP, esta informação foi obtida para o artigo através de uma entrevista feita em (2011) pelo Diário do Grande ABC.

\subsection{Pesquisa}

Os dados do projeto foram coletados por meio de umas pesquisas survey elabor distribuída para 116 usuários, os gráficos apresentados no artigo fora o levantamento dessas informações nas áreas de pesquisa a qual melhor se encaixavam.

\subsection{Design}

Segundo Niemeyer (1998), Design significa projeto e configuração se distinguindo drawing - desenho, representação de formas por meio de linhas e sombras. Entende -se que design, compõe-se de criar, projetar e planejar produtos com o objetivo de solucionar um determinadó problema.

\subsubsection{Design de Interface}

Em suma, esta parte do artigo teve como base o requisito de que o design de interface é a interação entre o humano e computador de forma eficaz, usando os princípios de Nielsen. Desta forma, o projeto criando explorou os conceitos de minimalismo e psicologia das cores para interface mais confortável e simples. Para que, assim, a informação excessiva fosse diluída Griefrołma prática.

\subsubsection{Design de Interação}

O design de interação fundamenta-se em propor ao usuário uma experiência melhor na forma de como ele trabalha, comunica-se ou interage com o computador no seu cotidiano. Sendo 13o Congresso Brasileiro de Pesquisa e Desenvolvimento em Design, Joinville (SC) 
assim, o estudo em que o artigo foi estabelecido procura explorar a "complexidade do simples" que visa diminuir ao máximo a dificuldade que o usuário tem em processar a informação correspondendo sempre a capacidade de como o usuário irá lidar com essa informação, pois, para atingir um número maior de usuários deve-se levar em conta idade, sexualidade e o nível de experiência que o mesmo tem com a mecânica.

\subsubsection{Protótipo}

Com base nos dados levantados em meados de novembro de 2017, fora feito o conceito de um aplicativo em que a pesquisa survey, e os princípios do design foram empregados. Segue em anexo algumas de suas telas na metodologia do trabalho.

\section{Materiais e Métodos}

Para este projeto que aborda a elaboração de um meio digital para os problemas de conhecimento em mecânica dos motoristas e estudantes, foram adotados os estudos de SCATENA, NIEMEYER, BONSIEPE como modelo estrutural quanto ao design para desenvolvimento de um produto original, e estudo do portal Ux Design como auxílio.

Para fundamentar o projeto foi realizado uma pesquisa com usuários de diversos tipos, tais como, motoristas experientes, novatos e estudantes de autoescola de ambos os sexos, com faixa etária entre 18 a 45 anos. Os dados da pesquisa foram levados em conta num contexto de ensino e aprendizado a fim de apoiar o desenvolvimento no conhecimento dos usuários de forma escalar, pois, segundo o filósofo Vilém Flusser, o ato de informar como a imposição de formas claras e específicas à matéria amorfa, isto é, conglutinar a informação bruta de uma forma compreensível a todas as pessoas. E para este projeto, a fim de realizar o que propõe, a metodologia foi realizada nas seguintes etapas: levantamento de dados, análise de dados, e planejamento do produto, uma vez que a programação não era o propósito deste projeto.

\subsection{Pesquisa}

\subsubsection{Levantamento de Dados}

Para este projeto foi aplicado um questionário com 116 pessoas para definir o público alvo, focado em criar uma solução simples e prática para que os usuários possam resolver os problemas sem ter maiores dificuldades durante o processo. Isto irá permear as verificações de alternativas mais viáveis para resolver os problemas dos usuários, baseando-se nas pesquisas que se procederam.

\subsubsection{Levantamento de Dados}

Figura 1 - Gráfico retirado da pesquisa survey

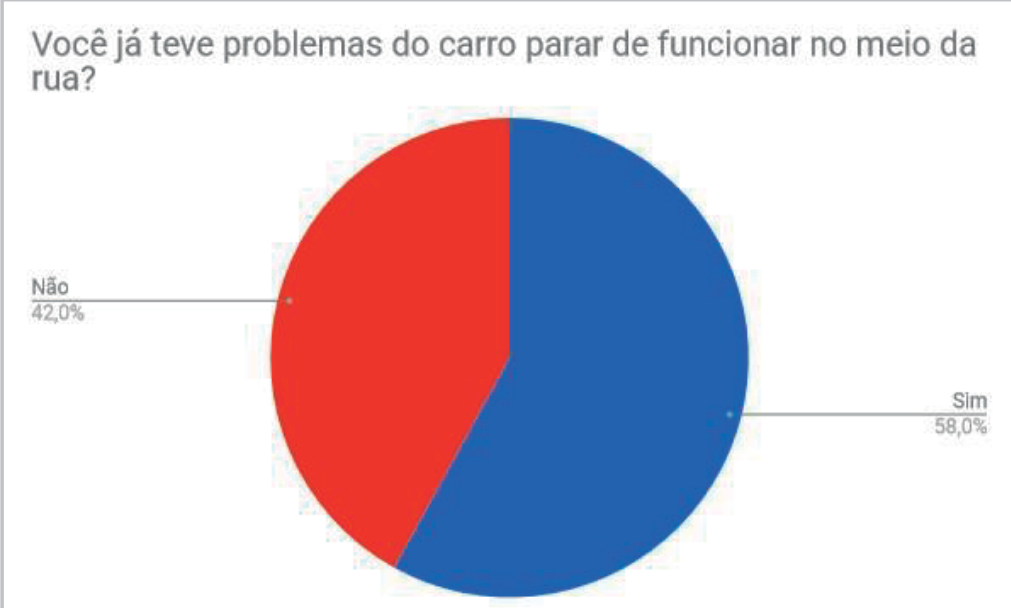


Fonte: Gráficos elaborados pelo autor, com base na pesquisa realizada

Figura 2 - Gráfico retirado da pesquisa survey

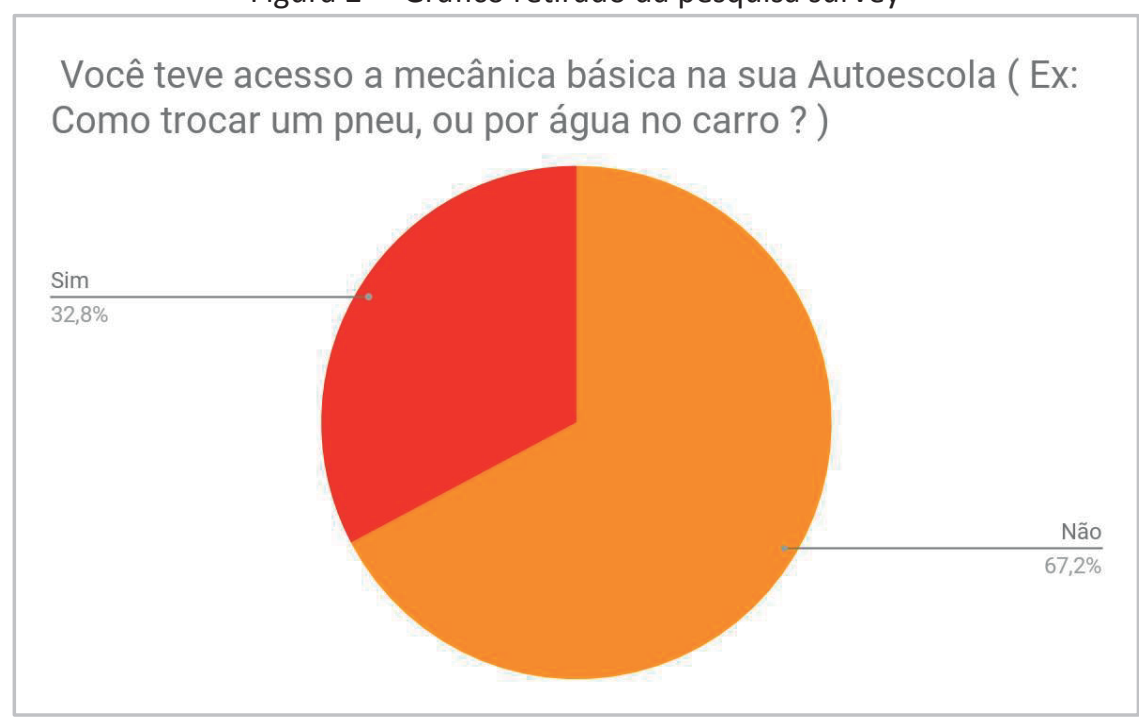

Fonte: Gráficos elaborados pelo autor, com base na pesquisa realizada

Análise dos resultados: Inicialmente no projeto foi realizado um levantamento de como os problemas mecânicos afetavam a vida dos motoristas, e foi contraposto duas perguntas, que era de se os motoristas tiveram acesso ao ensino básico de como proceder em problemas eventuais que pode acontecer com um veículo, tais como trocar um pneu ou por água no carro, com uma margem de $60 \%$, os motoristas afirmaram que não tiveram tal conteúdo repassado a eles, e na outra pergunta $58 \%$ dos motoristas já passaram por situações de que o veículo parou de funcionar meio da rua os expondo ao perigo. Desta forma, os dados afirmam que um pouco mais da metade dos motoristas já enfrentaram problemas reais, e que também muitos motoristas saíram da autoescola sem saber como proceder nessas ocasiões.

Princípio: Mapeamento do nível de conhecimento dos motoristas. 5.1.3

\section{Análise de Materiais Didáticos}

Figura 3 - Gráfico retirado da pesquisa survey

Contagem de Como você avaliaria seu conhecimento de mecânica, sobre o carro?

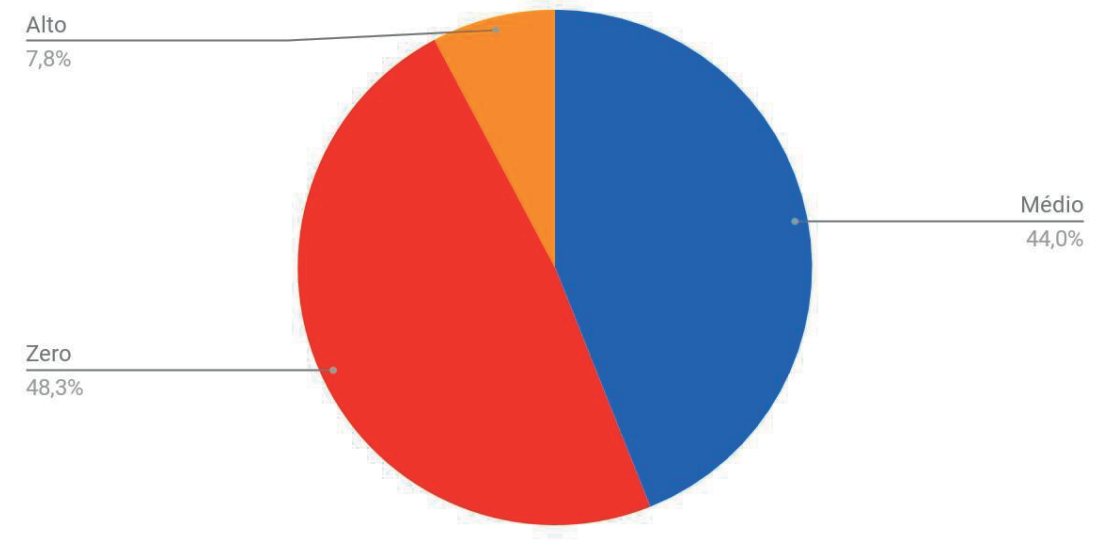

Fonte: Gráficos elaborados pelo autor, com base na pesquisa realizada 
Figura 4 - Gráfico retirado da pesquisa survey

Contagem de Alguma vez você já foi enganado por um serviço feito por oficinas?

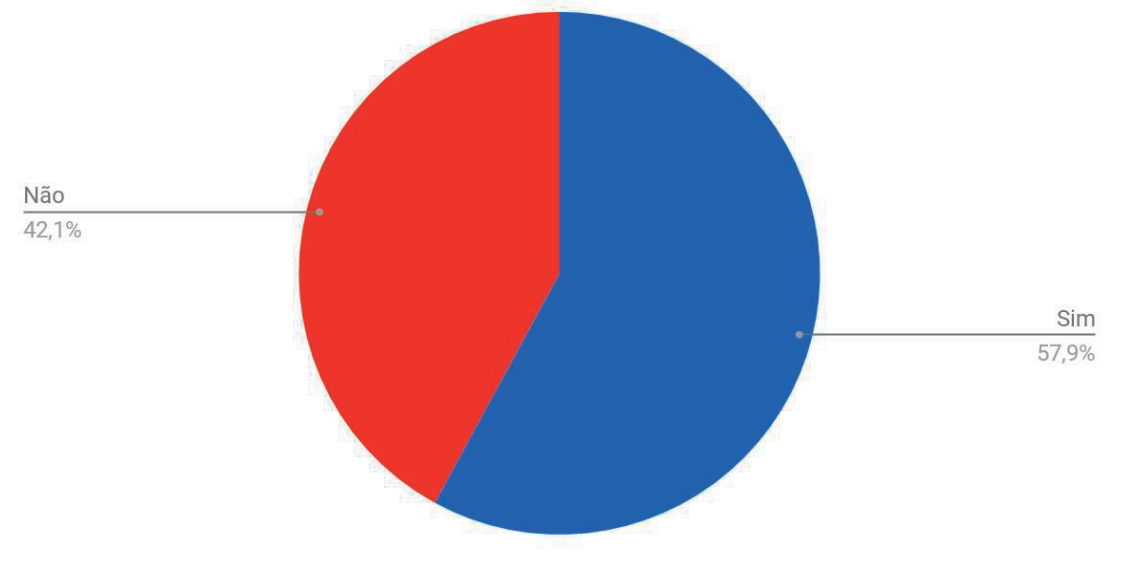

Fonte: Gráficos elaborados pelo autor, com base na pesquisa realizada

Análise dos resultados: Na última parte do projeto foi feito um levantamento da qualidade do material didático disponível para os motoristas e alunos de autoescola. A maioria deles possui conteúdo extensivo ou complexo, como por exemplo, o manual do proprietário anexado nas referências, esse tipo de distribuição de material didático acaba que afastando o motorista da vontade de conhecer mais. Nos dados levantados da pesquisa, apenas $7,8 \%$ dos entrevistados consideravam que tivesse conhecimentos mais avançados de mecânica. A carência desse conhecimento expõe os motoristas a mecânicos mal-intencionados, que se aproveitam dessa ingenuidade para lucrar mais em cima dos mais leigos, situação em que 57,9\% dos entrevistados afirmam ter passado alguma vez na vida.

Princípio: Provar a ineficiência do material didático disponibilizado atualmente.

\subsection{Levantamento Bibliográfico}

Foi realizada a pesquisa de informações na Internet sobre dados do trânsito em portais tais como: DETRAN - GO, Onsv.org, Portal do trânsito, Editora Dince e Portal G1 para notícias. E levantamentos de senso comum sobre acidentes e problemas usuais dos motoristas. Essas informações serviram de base para a pesquisa com os usuários e estruturação do artigo. Quanto ao Design, foram realizadas pesquisas na internet para os diversos temas abordados dentro da área para este artigo, sendo primeiramente os conceitos de Usabilidade no Uxdesign Brasil, e nos livros Design: do material ao digital BONSIEPE, Design no Brasil: Origens e instalação, NIEMEYER. PRINCÍPIOS DE DESIGN: Interação Humano-computador de SCATENA para embasamento teórico.

\subsection{Solução do Projeto}

Para a resolução deste projeto foram reunidos os dados coletados, e para tal, fora apresentado a proposta de uma plataforma mobile, inicialmente para smartphones ou mesmo um site. Com o propósito de empregar os conceitos de UI/UX na sua estrutura de ensino priorizando simplificar os conteúdos de mecânicas através de um método de ensino mais amigável, onde o objetivo principal seria atender as expectativas do usuário, mostrando ele que pode chegar facilmente a informação que procura, não o sobrecarregando de informação pois isso o faria perder 
o foco. É importante salientar que os usuários têm diferentes níveis de habilidade, e que a idade pode ser um fator relevante na hora de projetar a experiência do projeto.

\subsubsection{Estratégia}

Figura 4 - Wireframe retirado do projeto

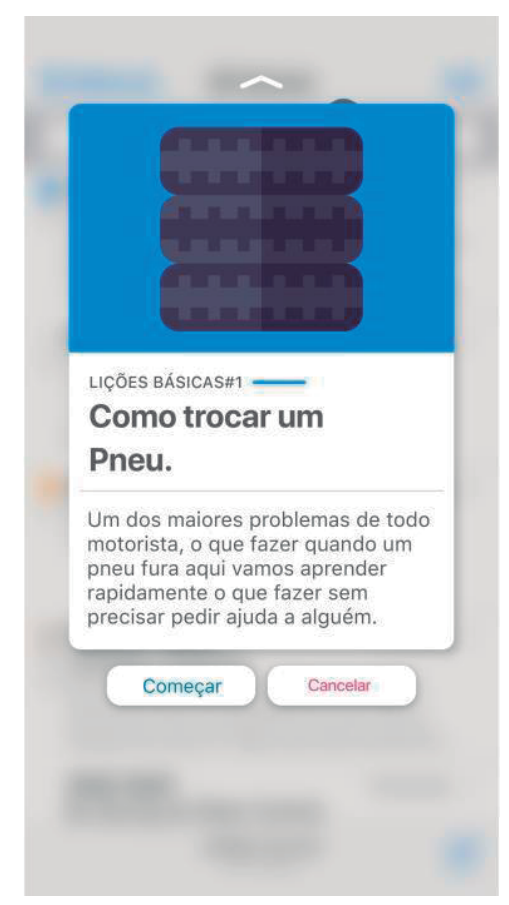

Fonte: Projeto elaborado pelo autor

A tática usada será o uso da experiência do usuário em forma de conversa. O aplicativo terá enfoque em ter linguagem mais amigável e informal, e a interface não seria somente um chatboot, mas também uma interface convencional que encurtaria o tempo de adaptação do usuário com o aplicativo. "Um chatbot é uma ótima oportunidade para sua marca expressar sua personalidade e estabelecer um contato mais humano com os usuários do outro lado da conversa " afirma Marco Fuzatto (2017). Sendo assim, priorizar a experiências do usuário e adaptála para que o mesmo possa usar o aplicativo continuamente.

\subsubsection{Interação UI/UX}

Figura 6- Gráfico retirado da pesquisa survey

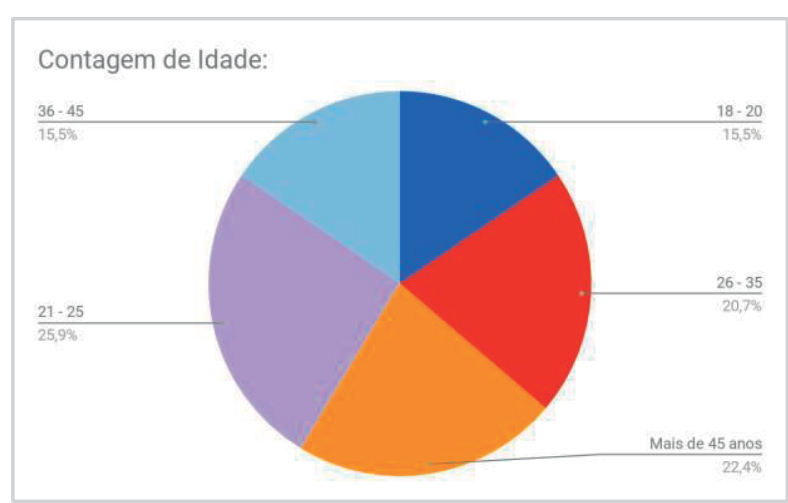

Fonte: Gráficos elaborados pelo autor, com base na pesquisa realizada 


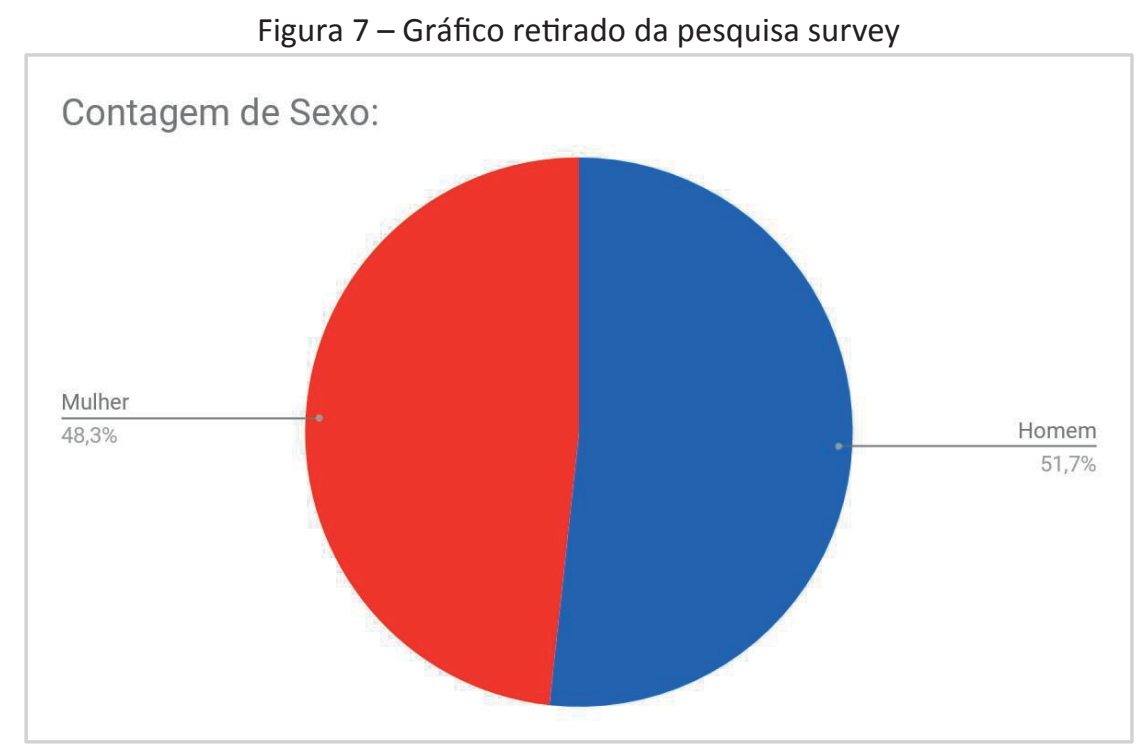

Fonte: Gráficos elaborados pelo autor, com base na pesquisa realizada

Análise dos resultados: Esta parte do projeto tem como foco definir o perfil do usuário que tinha dificuldades com a falta de informações, e os resultados permitiram que a perspectiva do foco da proposta apresentada não se fechasse apenas em um nicho específico. Dos 116 entrevistados foi difícil definir uma faixa etária predominante, pois a maior porcentagem fora das pessoas de entre vinte e um a vinte e cinco anos com a fatia de $25,9 \%$, apenas um pouco acima das pessoas de vinte e seis a trinta. Desta forma pode se definir que todas as idades tinham problemas na hora de lidar com os problemas do seu veículo. Agora, na questão do sexo, houve uma parcela bem distribuída de entrevistados que pode ser afirmar que os dois grupos enfrentam problemas parecidos no momento em que o carro passa por problemas mecânicos.

Tendo em vistas essas informações, elas serviram para definir como proceder no momento de elaborar uma interface, pois ela não poderia ser tão complexa a ponto de confundir o público mais velho, e sendo mais atrativa e rápida para não perder o foco do público mais novo.

Princípio: Definir o público alvo.

\subsection{Estrutura da Solução}

A elaboração deste projeto utilizará os princípios de Garrett, visto que a obtenção dos dados deste, foram obtidos com pesquisas e questionários direcionados para motoristas recém habilitados e mais experientes sobre os seus conhecimentos acerca do funcionamento da parte elétrica, mecânica e manutenção do veículo. Os dados coletados servirão para criar uma experiência mais fidedigna para os diferentes tipo de usuários. O projeto foi definido nas seguintes etapas:

\subsubsection{Escopo}

A finalidade do aplicativo é facilitar a vida do usuário motorista, desde o mais leigo, até o mais experiente provendo aos mesmo uma plataforma que oferece ajuda tanto na educação como na manutenção do mesmo, evitando estresses e perda de tempo localizando tudo em apenas um lugar. 


\subsubsection{Estrutura}

O aplicativo poderia coletar dados ao mesmo tempo em que facilita a vida do usuário, permitindo cataloga-los por experiência e indicar o conteúdo mais apropriado para o seu nível de conhecimento.

A indicação de mecânicos seria outro mecanismo a parte no mesmo aplicativo onde a localização dos usuários mostraria às oficinas mais próximas permitindo que ele tivesse acesso a feedbacks de outros usuários precedentes, as avaliações serviriam para catalogar e evitar que os usuários se dirijam para mecânicos desonestos resultando em estresses e perdas financeiras

Figura 8 - Wireflow retirado de planejamento da solução mobile

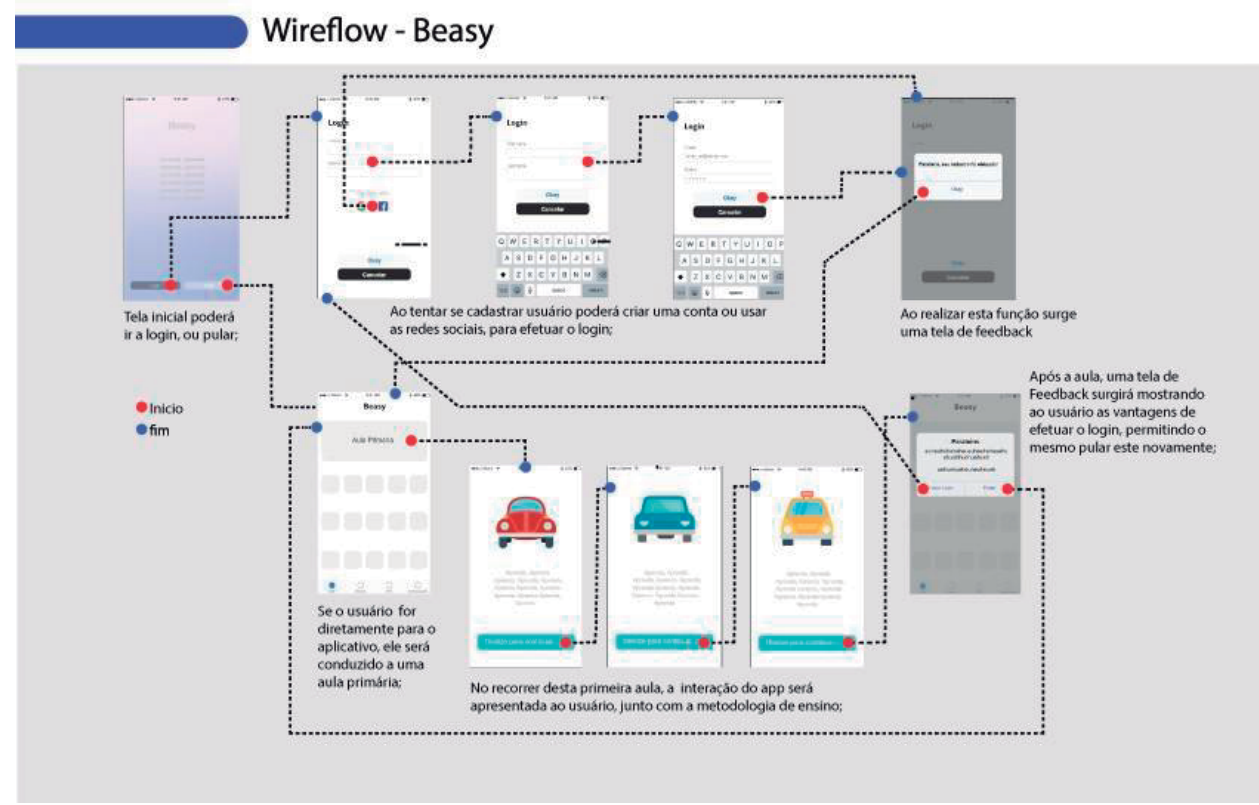

Fonte: Projeto elaborado pelo autor

Todavia, também serviria para que as oficinas possuam seu próprio controle de qualidade, corrigindo seus erros e verificando onde há mais procura de serviços, catalogando e obtendo dados das necessidades dos usuários oferecidas propriamente por eles.

\subsubsection{Esqueleto}

A resolução sobre como transmitir o conteúdo para os usuários terá foco na simplicidade, e a transmissão do conteúdo educacional será dada através de Cards com pequenas quantidades de informação. Uma forma simples de oferecer o conteúdo pouco a pouco, visando transformar uma informação extensa e complexa em uma mensagem mais fácil de assimilar, evitando assim que o usuário desista ou perca o foco.

\subsubsection{Estética}

A estética do produto será uma das partes mais importantes visto que a mensagem será transmitida através desse meio. O uso dos Cards terá um visual simples com ilustrações para facilitar 
o entendimento de como manusear ou executar determinadas funções ou peças, e o uso das cores será utilizado para categorizar as informações e destacar o que é necessário.

Figura 9 - Mockup de Apresentação do Conteúdo Educacional

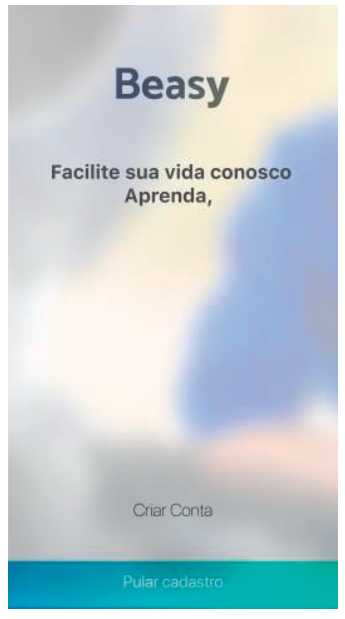

Fonte: Projeto elaborado pelo autor

Figura 10 - Mockup de Apresentação do Conteúdo Educacional

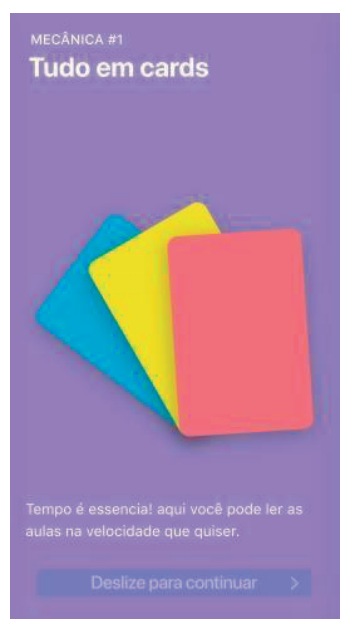

Fonte: Projeto elaborado pelo autor

Figura 11 - Mockup de Apresentação do Conteúdo Educacional

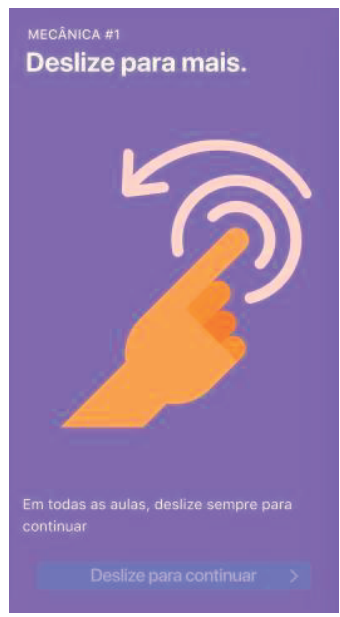

Fonte: Projeto elaborado pelo autor 
A interface será em Flat Design pois irá priorizar as informações deixando apenas o que é relevante visível e também economizando dados e bateria do dispositivo do usuário tendo em vista que excesso de informação poderia comprometer a experiência do usuário em situações como a pouca bateria do dispositivo ou sinal de má qualidade.

\subsubsection{Execução}

Figura 12 Mockups de Apresentação do Conteúdo Educacional

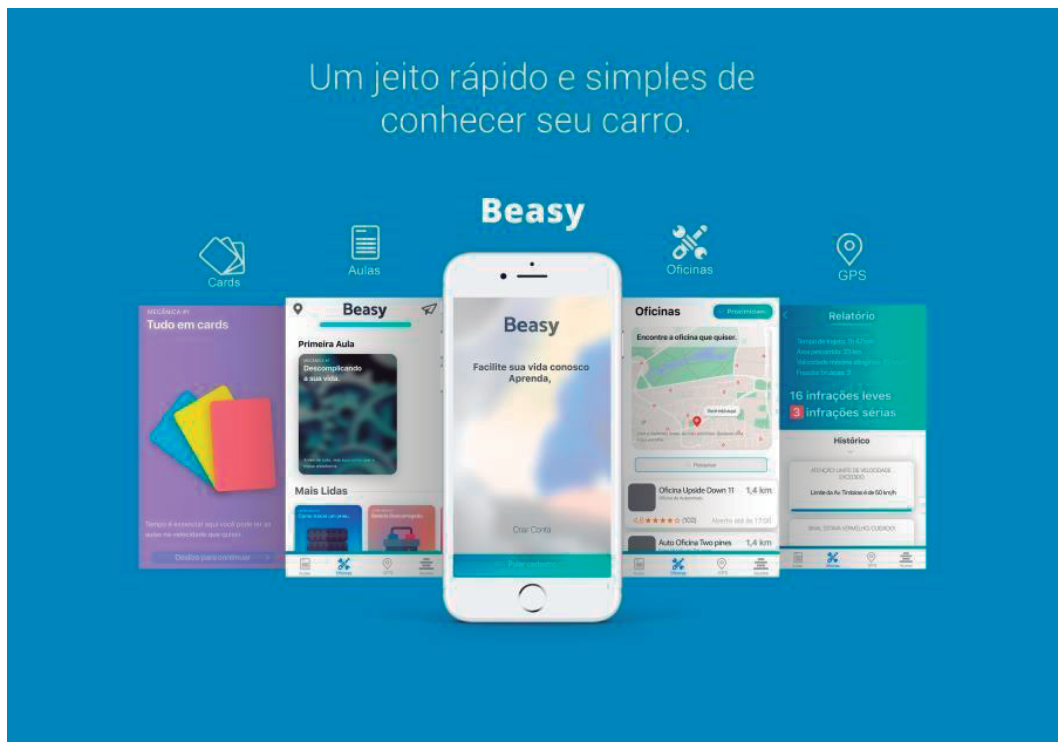

Fonte: Mockups elaborados pelo autor

Segundo Bonsiepe (1997) a interface "deveria permitir ao usuário obter uma visão panorâmica do conteúdo, navegar na massa de dados sem perder a orientação e, por fim mover-se no espaço informacional de acordo com seus interesses". Logo a execução deste projeto seria aplica a solução no dia a dia dos usuários, para que avaliem se a solução é realmente cabível na prática, $\notin$ avaliar em quais pontos precisam melhorar, alterar ou mesmo descartar.

\section{Considerações Finais}

Neste artigo foram apresentados os dados de um problema que não é novo, e que tem prejudicado um público que possui veículo ou está em meio ao processo de tirar a sua carteira de motorista e não sabe como ele funciona nem nos conceitos mais básicos da mecânica do mesmo e acaba exposto aos problemas já citados, que são prejuízos financeiros e nos casos mais extremos os danos físicos. Para tal, foi apresentado a proposta de uma plataforma para ajudar os motoristas a evitarem os infortúnios já citados, e para isso os ajudando usando conceitos de User Experience na proposta. Diante disso foram feitas pesquisas em sites relacionados a área e em pesquisas de orgãos reguladores do trânsito, mas também em sites de UX e em artigos publicados com foco nessa área ,como também no contexto educacional para solidificar a idéia proposta pelo artigo.

Juntamente com as pesquisas feitas e os dados obtidos com os entrevistados, viu-se que a grande carência dos mesmos quanto ao conhecimento desses conceitos de mecânica e cuidados básicos com o carro deve-se à barreira instrucional. Tendo em vista isso, o projeto utilizou os conceitos de aprendizado simplificado amplamente difundido nos artigos e estudos de UX citados no levantamento bibliográfico. Consequentemente fora elaborada uma proposta que pudesse ajudar os estudantes e motoristas de forma prática e que abrangesse a solução mais cabível para todos os públicos-alvo. 
Pois essa proposta aqui apresentada, também tem como foco ser distribuída para os órgãos educacionais responsáveis pelo trânsito e pode contribuir para trabalhos futuros tanto em plataformas mobile como Android e iOS, como também, pode ser adaptada para outras plataformas como sites ou mesmo dentro de Autoescolas. Com isso, conclui-se que há uma deficiência no sistema educacional do trânsito e que esse prejuízo por parte dos motoristas poderia ser contornado sem maiores problemas, apenas com a educação e de como ela é passada à cada um dos alunos, pois a forma como você aborda um determinado assunto pode ser o diferencial que o faz se afastar, ou interessar pelo mesmo. Independentemente de quão necessário possa ser o assunto para o motorista.

\section{Referências}

FUZATTO, Marco. Motorista deve conhecer mecânica, 2011. Disponivel em (http://www.dgabc.com.br/Noticia/11863/motorista-deve-conhecer-mecanica). Acesso em 10 dez. 2017.

EDITORA DIN.CE. Noções de Mecânica. Disponivel em (http://www.editoradince.com.br/arquivos_loja/15543/arquivo/nocoesdemecanica.pdf). Acesso em 15 jan. 2018.

MARUM, Denis. Cuidado com o golpe do falso mecânico, 2014. Disponivel em (http://g1.globo.com/carros/blog/oficina-do-g1/post/cuidado-com-o-golpe-dofalsomecanico.html). Acesso em $11 \mathrm{dez} .2017$.

BONSIEPE, Gui. Design: do material ao digital. Florianópolis, 1997. Disponivel em (https://pt.scribd.com/doc/124374053/Gui-Bonsiepe-Design-Do-Material-ao-Digital). Acesso em 9 fev. 2018.

LOPES, Lucas. UX como uma forma de conversa. 2017. Disponivel em (https://brasil.uxdesign.cc/uxcomo-uma-forma-de-conversa-194ef9dda40). Acesso em 15 nov. 2017.

TEIXEIRA, Fabricio. UX e chatbots: boas práticas para desenhar interfaces conversacionais. 2017. Disponivel em (https://brasil.uxdesign.cc/ux-como-uma-forma-de-conversa-194ef9dda40). Acesso em 15 nov. 2017.

TEIXEIRA, Fabricio. Design de informação: informando dados para torná-los mais eficientes e atrativos. 2013. Disponivel em (https://brasil.uxdesign.cc/design-deinforma\%C3\%A7\%C3\%A3oinformando-dados-para-torn\%C3\%A1-los-mais-eficientes-e-atrativose8eae342f150). Acesso em 15 nov. 2017.

FERREIRA, Iris. A complexidade do simples. 2013. Disponivel em (https://brasil.uxdesign.cc/acomplexidade-do-simples-fe236147583b). Acesso em 13 nov. 2017.

NIEMEYER, Lucy. Design no Brasil: Origens e instalação. Rio de Janeiro: 2AB, 2007. Acesso em 6 dez. 2017. 
SCATENA, Jean Miler. PRINCÍPIOS DE DESIGN: Interação Humano-computador. Disponivel em (https://www.passeidireto.com/arquivo/2767638/ihc---02---principios-de-design). Acesso em 20 fev. 2018.

FLUSSER, Vilém; CARDOSO, Rafael e ABI-SÂMARA, Raquel. Mundo Codificado: Por uma Filosofia do Design e da Comunicação. São Paulo: Cosac \& Naify, 2007. 